\title{
O início da revolução científica: questões acerca de Copérnico e os epiciclos, Kepler e as órbitas elípticas
}

(The Scientific Revolution: on Copernicus and the epicycles, Kepler and the elliptic orbit)

\author{
Felipe Damasio \\ Instituto Federal de Educação, Ciência e Tecnologia de Santa Catarina, Araranguá, SC, Brasil \\ Recebido em 2/6/2010; Aceito em 22/5/2011; Publicado em 6/10/2011
}

\begin{abstract}
A revolução científica pode ter datado seu início com o trabalho de Copérnico e o seu ápice ocorreu com Isaac Newton. Porém, muito tem sido discutido de forma imprecisa a respeito da motivação de Copérnico e Kepler para que desenvolvessem seus trabalhos. Neste artigo será descrito questões acerca da versão corrente de que a complexidade dos epiciclos do sistema ptolomaico seria a motivação principal para a revolução copernicana. Ainda é discutida a possibilidade de que na formulação por Kepler de sua primeira lei tenha havido inspiração em ideia de outra pessoa.
\end{abstract}

Palavras-chave: Copérnico, Kepler, epiciclos, elipse.

The scientific revolution could have dated its beginning with the work of Copernicus and its apex with the work of Isaac Newton. However, most discussions about the motivation of Copernicus and Kepler to develop their work have been inaccurate. This article describes issues regarding the current version of the complexity of the epicycles in the Ptolemaic system as the key issue that led to the Copernican revolution. It also raises a insight Kepler might have had to develop what would be known later as Kepler's first law.

Keywords: Copernicus, Kepler, epicycles, ellipse.

\section{Introdução}

A chamada revolução científica, ocorrida principalmente entre os séculos XVI e XVII, é a passagem da visão de mundo aristotélico para a ciência moderna na qual as questões científicas e as suas soluções devem ser apresentadas em linguagem matemática [1]. Esta revolução teve como ápice a obra de Isaac Newton (16431727) e suas leis do movimento e da gravitação universal [2]. No entanto, podemos dizer que tal revolução iniciou com Nicolau Copérnico (1473-1543) e encontrou em Johannes Kepler (1571-1630) seu verdadeiro revolucionário [3].

O termo Revolução Copernicana é usado repetidas vezes ao se referir ao impacto da obra de Copérnico na história da Ciência. Lakatos [5] chama a Revolução Copernicana como sendo a hipótese de que a Terra gira em torno do Sol e não o contrário, ou com maior precisão, a hipótese do referencial fixo do movimento planetário ser as estrelas fixas e não a Terra.

Hoje se sabe que a chamada revolução não se baseou em fatos novos. Kuhn chama a atenção que as predições de Ptolomeu eram tão boas como as de Copérnico, e inclusive [6, p. 96] "a astronomia ptolomaica é ainda hoje

\footnotetext{
${ }^{1}$ E-mail: felipedamasio@ifsc.edu.br.

usada para cálculos aproximados". Tanto a hipótese de Copérnico como a de Ptolomeu eram inconsistentes com muitos fatos observacionais conhecidos, como as posições do planeta Marte (Gingerich, apud Ref. [5]). Kepler já havia percebido estes erros, inclusive se queixando deles no prefácio das tabelas rudolfinas. Também existem evidências de que tabelas baseadas na hipótese de Ptolomeu eram mais precisas que aquelas que adotavam a hipótese copernicana (Gingerich, apud Ref. [5]). Comparações modernas mostram que as predições empíricas não melhoraram, tornando-se até piores em alguns casos [7]. Se as revoluções científicas consistem em descobrimento de novos fatos e de sua generalização ou de propor uma teoria científica mais provável dada pelas evidências disponíveis, então não existiu uma revolução copernicana científica [5].

Ainda existe a hipótese de que houvera algum experimento crucial para que o sistema de Ptolomeu fosse refutado e surgisse o de Copérnico. No entanto, um experimento crucial que poderia refutar definitivamente o sistema de Ptolomeu foi a medição da paralaxe estrelar, que ocorreu em 1838, quase trezentos anos depois da morte de Copérnico. Logo, se as revoluções científicas consistem em refutar uma teoria importante 
e sua substituição por uma outra, a revolução copernicana só ocorreu, na melhor das hipóteses, em 1838 $[5]$.

Copérnico questionou o modelo de Aristóteles (384 a.C.-322 a.C.), mas reteve muitas das concepções aristotélicas [4]. Copérnico não foi o primeiro a propor um modelo de Universo heliocêntrico. Antes dele, já na Antiguidade, outros tinham aventado tal hipótese, tal como Aristarco de Samos (c. 310-c. 250 a.C.) [8]. O modelo aceito por grande parte das pessoas durante séculos colocava a Terra em uma posição central. Porém, neste modelo o movimento irregular aparente dos planetas, ora progressivo, ora parado, ora retrógrado causava arranjos que foram causa de desconforto de muitos, entre eles Copérnico [6]. Estes arranjos, não eram os epiciclos, e sim os equantes.

É de uso corrente que a complexidade cada vez maior do sistema geostático de Claudio Ptolomeu (90168 d.C.) teria levado Copérnico a propor seu sistema. A veracidade deste argumento é discutida neste artigo, bem como quais foram os motivos que levaram Copérnico a propor seu sistema, já que, como já vimos, não foi devido a fatos novos, alguma crise com o sistema ptolomaico ou experimento crucial realizado. Nas palavras de Feyeranbend [7, p. 199]; "Nem novas observações nem a incapacidade de Ptolomeu de cuidar daquilo que lhe era conhecido são a razão para o desconforto de Copérnico. A dificuldade que ele percebe encontra-se em outro lugar". Neste artigo será discutido aonde se encontrava o desconforto de Copérnico com o sistema ptolomaico.

Outra questão relevante sobre a obra de Copérnico está no motivo pelo qual ele não foi capaz de perceber que as órbitas dos planetas são elípticas, ao invés de circulares, cabendo a Kepler tal proposta. Uma possível inspiração de Kepler na formulação da sua primeira lei é apresentada no final deste artigo.

\section{O revolucionário involuntário}

Quando Copérnico propôs sua nova cosmologia heliocêntrica ele não intencionava subverter a Astronomia, pois era antes de tudo um conservador, nas palavras de Feyerabend [7, p. 192] "Copérnico era um cristão fiel e um bom aristotélico; tentou restaurar o movimento circular centrado à proeminência que certa vez tinha tido, postulou uma Terra em movimento". O motivo pelo qual um conservador causou a chamada revolução copernicana foi que Copérnico queria retomar as antigas ideias da filosofia grega, e foi a partir desta retomada que a revolução teve início. O principal papel de Copérnico foi o de inspirar os futuros astrônomos; a verdadeira revolução copernicana só ocorreria mais de meio século depois da morte de Copérnico com Galileu Galilei (1564-1642) e Kepler (1571-1630) [10].

Copérnico acreditava na concepção platônica que propunha que os movimentos celestes eram circulares e com velocidades regulares. Platão (século IV a.C.) havia adotado as ideias de Pitágoras de Samos (século V a.C.) - famoso pela proposição que ele ajudou a difundir. Para Pitágoras, o movimento dos astros deveria ser circular e uniforme (perfeito e regular), todos estes círculos deveriam ter um mesmo centro no qual estaria a Terra imóvel. Discípulo de Platão, Aristóteles (século IV a.C.) transformou as ideias pitagóricas adotadas por Platão em dogmas astronômicos que durariam mais de 2000 anos - os círculos só foram contestados por Kepler no século XVII d.C. [3].

Claudio Ptolomeu (90-168 d.C.) resumiu cinco séculos de astronomia grega geostática em seu livro que é hoje conhecido como Almagest (O majestoso). $\mathrm{O}$ grande desafio dos modelos geocêntricos gregos que adotavam movimentos circulares e uniformes não era explicar a trajetória aparente das estrelas fixas, do Sol e da Lua que se comportavam de maneira regular. O grande problema era explicar o movimento errante dos planetas. Para tentar explicar este balé cósmico com o modelo geocêntrico os astrônomos gregos tiveram que usar artifícios como o excêntrico, os epiciclos e o equante este último introduzido por Ptolomeu [10].

$O$ excêntrico (fora de centro) é a ideia de que a Terra, apesar de imóvel, não mais estava no centro de cada uma das órbitas mas em um ponto próximo do centro. Assim sendo, os modelos que usavam o excêntrico não podem a rigor ser chamados de geocêntricos, e sim deveriam ser chamados de geostáticos.

Adicionalmente a trajetória de cada corpo celeste era uma composição de movimentos circulares. Um destes formado por um círculo maior chamado de deferente, com centro em um ponto vazio particular, não a Terra. Círculos menores se deslocavam sobre os deferentes, estes círculos menores foram chamados de epiciclos, sobre o qual estaria a órbita dos astros (menos o Sol e a Lua que não necessitariam de epiciclos para dar conta de seus movimentos).

Ptolomeu, além de usar os excêntricos e os epiciclos (propostos possivelmente no século III a.C.), introduziu um conceito adicional com o objetivo de explicar melhor o movimento dos corpos celeste: o equante. $\mathrm{O}$ equante é um ponto deslocado em relação ao centro de cada um dos deferentes, em torno do qual o centro do epiciclo do planeta se desloca com velocidade uniforme. O planeta, conforme mostra a Fig. 1, move-se em um círculo pequeno (epiciclo), cujo centro está no círculo maior (deferente). O centro do epiciclo tem velocidade constante em relação ao ponto equante. Porém, um observador no planeta Terra está no lado oposto do centro do deferente [7]. Desta forma, o equante contempla a ideia do movimento uniforme, mas não mais em relação ao centro do deferente e nem em relação à Terra, mas em torno de um ponto vazio.

Então, a grande contribuição ptolomaica foi a divulgação em seu livro Almagest de um modelo funcional que podia descrever e prever com precisão satisfatória 
o movimento dos astros, além da introdução do conceito de equante. Este modelo geostático de Ptolomeu manteve-se desde o século II até o XVI. Veio a ser fortemente contestado por Copérnico, motivado em que o equante violava o antigo ideal grego de que todos os movimentos fossem uniformes em torno do centro.

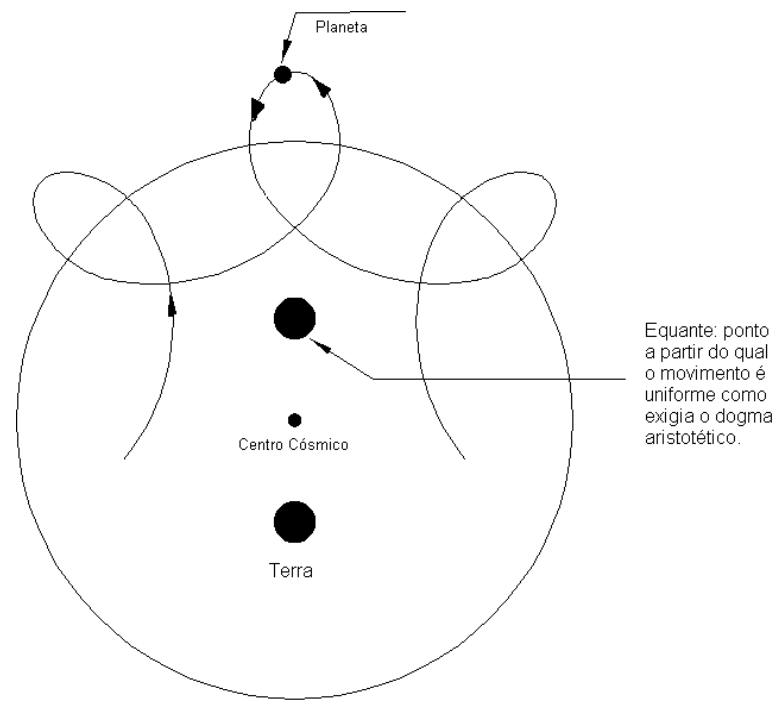

Figura 1 - Equante, epiciclos e excêntrico adotados pela astronomia grega (a figura não está em escala).

O maior mérito da obra de Copérnico foi o de retomar a astronomia matemática praticada pelos gregos opondo-se ao saber meramente especulativo. Copérnico não foi o primeiro a propor o movimento da Terra, como ele próprio admite no prefácio do De Revolutionibus sua obra revolucionária. Ele adiou a publicação desta obra o quanto pode temendo muito mais ser ridicularizado do que sofrer uma retaliação da Igreja Católica [11]. Antes da publicação de De Revolutionibus em 1543, Copérnico já havia feito circular por volta de 1519 um ensaio denominado Commentariolus com uma versão preliminar de seu sistema cosmológico [12]. Também já havia publicado um trabalho sobre matemática pura em 1542 chamado De Lateribus et Angulis Triangulorum Libellus [13]; este tratado sobre trigonometria demonstrava o grande domínio de matemática que Copérnico possuía, natural para um astrônomo neste período histórico onde o conhecimento de trigonometria era muito importante [14].

No Commentariolus, Copérnico mostra sua insatisfação com o modelo ptolomaico, apesar de admitir que ele fornecesse dados numéricos consistentes [7]. O grande desconforto de Copérnico residia, como já destacado anteriormente, no uso do equante que fazia, no sistema de referência da Terra, com que os movimentos dos planetas não fossem uniformes [15].

A insatisfação de Copérnico com o sistema ptolomaico não foi gerado por novas observações, as suas eram essencialmente as mesmas de Ptolomeu, as novas observações foram somente as de Tycho Brahe. Até Kepler, o sistema copernicano não aperfeiçoou as predições das posições planetárias feitas pelo sistema ptolomaico [6].

Copérnico criticava o sistema ptolomaico por razões teóricas, ele escreveu no Commentariolus; "Com efeito, essas teorias (dos ptolomaicos) não eram adequadas a menos que certos equantes também fossem concebidos; parecia então que um planeta não se movia com velocidade uniforme nem ao longo de seu próprio deferente nem relativamente a um centro real..." [7, p. 197].

Copérnico foi o primeiro a perceber que o movimento da Terra poderia ser a solução para os problemas astronômicos que há muito perturbavam os estudiosos do tema. O grande avanço da obra de Copérnico se refere à resolução do problema do movimento retrógrado dos planetas [10]. Para ele, o movimento retrógrado tinha que ser reduzido a outros movimentos, que fossem círculos centrados com velocidade angular constante ao redor do centro, condição violada por Ptolomeu e seu equante. Para Copérnico, movimento real é circular uniforme em torno do centro com velocidade angular constante [7].

A solução de Copérnico é simples para o movimento errante dos planetas, e uma consequência direta de seu modelo. O Sol está fixo e imóvel; em volta dele giram em círculos Mercúrio, Vênus, Terra (a Lua gira em torno da Terra que gira em torno de seu próprio eixo), Marte, Júpiter e Saturno. Cada planeta tem um período de revolução diferente, que aumenta com a distância ao Sol. A Terra e os planetas não giram em torno do Sol propriamente, mas em torno de um ponto vazio que está distante do Sol cerca de três diâmetros solares. Neste sistema os planetas (incluindo a Terra) descrevem círculos ao redor de um ponto imaginário, que não coincide com o Sol, sendo que este ponto revoluciona ao redor dele lentamente. Devemos chamar, a rigor, o modelo cosmológico de Copérnico de heliostacionário ou heliostático, esboçado na Fig. 2. Com seu novo modelo, Copérnico ainda pode estimar as distâncias dos planetas ao Sol, além do tempo de revolução de cada planeta [11].

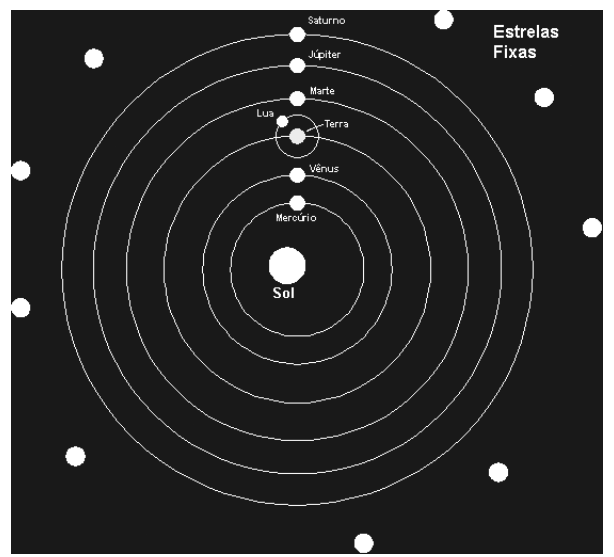

Figura 2 - Modelo copernicano. 
O movimento dos planetas no sistema copernicano é quase sempre progressivo visto da Terra, salvo quando nosso planeta ultrapassa os planetas com velocidade orbital menor (Marte, Júpiter, Saturno, Urano e Netuno - estes dois últimos ainda não descobertos na época de Copérnico) ou quando é ultrapassada pelos planetas mais rápidos (Mercúrio e Vênus), nestas situações os planetas parecem retroceder.

Apesar do sucesso em explicar o movimento errante dos planetas, Copérnico não fora capaz de provar que algumas importantes consequências dessa concepção heliostática estavam corretas. Entre elas havia a previsão de que Vênus deveria apresentar fases como a Lua e deveriam ser observadas grandes mudanças nos tamanhos aparentes de Marte e Vênus. Estas previsões somente foram corroboradas com as observações astronômicas de Galileu após 1610, portanto mais de setenta anos depois da morte de Copérnico. E mesmo assim, conforme nos mostra Lakatos, se estas observações foram cruciais para mostrar a superioridade do sistema de Copérnico perante o de Ptolomeu, a decisão da, então poderosa, Igreja Católica de colocar o livro de Copérnico entre os proibidos nesta mesma época foi uma horrível decisão $[5]$.

Outra importante previsão se devia a que o movimento anual em torno do Sol implicava em paralaxe das estrelas; de fato a paralaxe estelar somente foi observada em 1837 com o astrônomo alemão Friedrich Bessel (1786-1846) e a rotação da Terra em torno do seu próprio eixo demonstrada mecanicamente pelo pêndulo de Foucault somente em 1851 [16].

A disseminação do copernicanismo teve uma consequência ideológica, além das astronômicas. Como neste sistema a Terra era apenas mais um entre os planetas, o ser humano havia sido deslocado de sua posição de destaque [15].

\section{O mito dos epiciclos nos epiciclos}

É lugar comum que a motivação de Copérnico para a proposição de sua concepção heliostática fosse sua insatisfação com os epiciclos e que de fato ele os abolira, e que a aceitação de sua teoria estava no fato de ela ser mais simples que a de Ptolomeu. Como bem notou Arthur Koestler em Os Sonâmbulos [17], Copérnico não reduziu o número de círculos do sistema ptolomaico, aumentando este número inclusive, pois utilizou largamente os epiciclos. De acordo com Feyeranbend [7, p. 199]; "Copérnico elimina excentro e equante e os substitui por epiciclos". Esta explicação para a revolução copernicana, que apela para um critério de simplicidade baseado na inexistência de epiciclos na proposta heliostática, não é sustentável então.

Não existe registro sobre Copérnico criticando o excesso de epiciclos do modelo ptolomaico. Ele próprio deixa claro já no Commentariolus que a sua grande crítica ao modelo de Ptolomeu dizia respeito ao conceito de equante [18]. A chamada revolução copernicana só foi possível por um retorno ao platonismo [16]. Porém a questão sobre a origem deste mito dos epiciclos deve ser analisada e discutida. Ela parece ter origem no manuscrito de Copérnico Commentariolus distribuído em torno de 1519

Commentariolus ficou esquecido durante séculos, sendo a sua existência praticamente ignorada até sua "redescoberta" em 1880. No ensaio, Copérnico finaliza com a frase: "Vejam! Apenas 34 círculos são necessários para a explicação da estrutura em torno do Universo e a dança dos planetas!" [3].

Uma leitura inocente desta afirmação pode levar a impressão de que Copérnico está comemorando uma grande simplificação, diminuição do número de círculos, de seu sistema quando comparado ao de Ptolomeu. A afirmativa final no Commentariolus pode dar impressão de que Copérnico parece exaltar que são necessários apenas 34 círculos, e por consequência, o sistema de Ptolomeu deveria ter um número bem maior de círculos.

A lenda parece ter sido oficializada quando em 1964 a Enciclopédia Britânica afirmou que no sistema de Ptolomeu cada planeta tinha entre 40 e 60 epiciclos. E que o mecanismo geométrico de Ptolomeu tornara-se incômodo por sua complexidade [3]

Alguns livros parecem reforçar a ideia de que a adoção do sistema heliocêntrico foi motivada pela sua simplicidade em relação ao de Ptolomeu. Como em um dos livros didáticos mais adotados nas escolas do Brasil [19, p. 207] "O astrônomo polonês, Nicolau Copérnico, no século XVI, apresentou um modelo mais simples para substituir o sistema de Ptolomeu".

Em $O A B C D$ da Astronomia e Astronomia, um livro de divulgação científica se lê $[20$, p. 42]; "[...] cientistas perceberam a simplicidade do sistema de Copérnico perante o complicado sistema dos epiciclos de Ptolomeu. [...] não havia nada além da simplicidade, que indicasse sua superioridade perante a teoria de Ptolomeu".

Existe uma interpretação de que o sistema de Ptolomeu podia acomodar qualquer fato novo aumentando os epiciclos e equantes, de acordo com Lakatos, a afirmação de que o sistema de Ptolomeu podia ser manipulado para acomodar qualquer observação planetária incorporando um número indefinido de epiciclos é um mito. Lakatos cita a reconstrução das tabelas da Idade Média por Gingerich para provar esta afirmação, pois ela mostra que estas tabelas usavam um sistema com epiciclo único [5]

Para tentar estimar o número de círculos no sistema geostático no final da Idade Média, e se de fato existiria necessidade de haver epiciclos em epiciclos Owen Gingerich [3] usou simulação computacional. Gingerich utilizou o computador do Observatório Smithsoniano para recalcular as tabelas alfonsinas. Estas foram construídas durante o século XIII por cerca de cinquenta astrônomos sob encomenda do Rei de Castela Afonso 
$\mathrm{X}$ com o objetivo de revisar as tabelas de Ptolomeu [19]. Os resultados da simulação feita por Gingerich foi que as tabelas alfonsinas eram puramente as de Ptolomeu, sem nenhum detalhe adicional Com base neste dado, Gingerich calculou a previsão das tabelas alfonsinas para diversos astros durante várias décadas do século XVI, época em que viveu Copérnico. Após isto comparou com os dados de cálculos mais modernos. Os resultados mostravam apenas poucas discordâncias, como em fevereiro e março de 1504 quando as previsões da tabelas alfonsinas discordavam da posição real de Saturno em um grau e meio e de Marte em dois graus, apesar de estar de acordo com a posição real de Júpiter.

A simulação de Gingerich é um bom indicador que não existia epiciclos em epiciclos no sistema de Ptolomeu como proclama a lenda. Não havia necessidade, pois as previsões das tabelas ptolomaicas eram razoavelmente consistentes com as posições reais. Ademais, não existe registro de que tenha havido grande discrepância entre as posições reais das tabelas ptolomaicas e as posições reais dos astros [3].

Kuhn já chamava a atenção para que a motivação de Copérnico não tivera qualquer razão astronômica. Tampouco uma insatisfação com descobertas recentes que poderiam ter promovido os epiciclos nos epiciclos, "nenhuma descoberta astronômica fundamental, nenhuma espécie nova de observação astronômica persuadia Copérnico da imperfeição da antiga astronomia ou da necessidade de uma mudança" (Ref. [22] apud Ref. [16])

Então nos resta especular o que estaria comemorando Copérnico na última frase de seu Commentariolus. Certamente não era uma grande simplificação de um sistema ptolomaico complexo, pois ele não existia desta forma. O que ele poderia estar comemorando era que seu sistema conseguia explicar todos os movimentos celestes com um número reduzido de círculos: entretanto em nenhum momento ele estaria fazendo uma comparação com seus antecessores.

\section{O surgimento das elipses em detri- mento dos círculos perfeitos}

Copérnico não pôde prever as órbitas elípticas por não ser tão copernicano quanto Kepler e outros de seus sucessores. O seu ideal platônico do movimento circular e uniforme dos astros está bem claro em suas palavras em De Revolutionibus "é impossível que um corpo celeste se mova de forma irregular por uma única esfera e nossa mente se estremece com esta expectativa" [3].

Mesmo que Copérnico de alguma forma se libertasse de suas crenças platônicas, dificilmente ele poderia ter tido condições técnicas de propor o movimento elíptico dos corpos celestes, hoje descrito pelo que ficou conhecido como $1^{a}$ lei de Kepler. Os dados de observações astronômicas disponíveis para Copérnico continham erros demais e de origens diferentes. Alguns já eram impre- cisos em sua origem; outros que tinham sido adquiridos com precisão haviam sido transcritos e/ou traduzidos de maneira equivocada [11].

Para que a lei das elipses pudesse ser proposta teria que surgir dados precisos e uma mente que não se estremecesse frente à ruptura com os ideais platônicos. A espera findou respectivamente com o dinamarquês Tycho Brahe (1546-1601) e o alemão Johannes Kepler.

Tycho construiu um catálogo de dados astronômicos muito preciso e com uma continuidade jamais vista antes. Havia revisado os catálogos estrelares e calculado de maneira mais precisa a posição de mais de mil destas estrelas.

Kepler constituiu-se no arquiteto teórico para a obra observacional de Tycho. Para Kepler, não bastava descrever o movimento celeste, sendo também necessária a busca de suas causas. Sua concepção desta causa foi a de uma força entre o Sol e cada planeta, crendo que se moviam mais lentamente quanto mais afastados estivessem do Sol, pois a força solar diminuía com a distância - ideia esta que mais tarde foi magistralmente desenvolvida por Newton.

Além de revolucionário, Kepler foi um unificador. Ele uniu a Astronomia com a Física, sendo assim o primeiro astrofísico da história da ciência. Porém, sem as observações de Tycho, Kepler jamais teria proposto as leis do movimento planetário [23].

Kepler foi apresentado ao sistema copernicano por seu professor na Universidade de Tübbigen, Michael Maestlin, vinte anos mais velho que ele. Seu livro Epitome Astronomie era usado como referência em diversas instituições de ensino na Europa, e adotava o sistema ptolomaico como referência. No entanto, Maestlin apresentava a seus alunos o sistema copernicano, e o defendia reservadamente. Kepler viu vantagens matemáticas no sistema de Copérnico em relação ao de Ptolomeu, e aderiu ao copernicanismo por também ser um neoplatônico [16].

A obra de Platão teve grande influência sobre Kepler. Ele tentou associar os sólidos platônicos (que são cinco) com o intervalo entre os planetas até então conhecidos (que eram seis). Para Kepler, não poderia ser coincidência haver cinco sólidos platônicos e o mesmo número de intervalo entre os planetas. Para ele esta coincidência dos números era uma explicação razoável para a existência de apenas seis planetas e não vinte e um [11]. Na obra que Kepler publicou em 1597, chamada de Mysterium Cosmographicum percebe a grande influência platônica nas propostas de Kepler.

Quando Kepler aceitou o convite de Tycho para se juntar ele, ele pretendia usar as observações de Brahe para melhorar seu modelo planetário construído em torno dos sólidos platônicos. No entanto, Tycho o encarregou do estudo da órbita de Marte [11].

Em uma troca de cartas com Galileu, Kepler se mostra um entusiasta do sistema cosmológico de Copérnico. Em carta datada de 13 de outubro de 1597 ele inclu- 
sive incentiva o receoso Galileu a assumir publicamente o copernicanismo já que o gênio italiano havia confessado em carta anterior a sua adesão a tais ideias. Apesar do incentivo de Kepler, Galileu só viria a defender publicamente o copernicanismo após 1610 [23].

Em Astronomia Nova (1609), que forma junto com De Revolutionibus de Copérnico e os Principia de Newton os três mais importantes livros da revolução científica dos séculos XVI e XVII, Kepler descreve a descoberta da órbita elíptica de Marte como se "tivesse acordado de um sonho". Kepler tentou por incansáveis vezes encontrar uma órbita circular excêntrica para Marte com base nos dados de Brahe. De acordo com o próprio Kepler em Astronomia Nova foram mais de setenta tentativas.

É interessante especular como Kepler desistiu da órbita circular para adotar a possibilidade da órbita elíptica. Para tanto, uma conjectura apresentada por Gingerich [3] ao analisar a cópia do De Revolutionibus que pertenceu a Kepler, hoje na cidade alemã de Leipzig, pode nos dar algumas pistas. Kepler não foi o primeiro dono deste exemplar; ele deve tê-lo ganho de presente de um familiar comerciante de livros. Um dono anterior a Kepler que fez muitas anotações no livro, foi um professor de Matemática da Universidade de Wittenberg chamado Jerome Schreiber

Uma das anotações mais interessantes da cópia do De Revolutionibus que pertenceu a Kepler foi feita por ele próprio, na seção inicial chamada Ad lectorem. Nesta seção era informado ao leitor que o livro se tratava meramente de uma hipótese matemática que não pretendia descrever o que realmente acontecia no mundo físico. "Estas hipóteses não precisam ser verdadeiras, nem mesmo plausíveis; é suficiente que os cálculos batam com as observações" advertia parte do texto.

Durante anos se pensou que o Ad lectorem havia sido escrito pelo próprio Copérnico, porém Kepler revelou em 1609 que o autor havia sido um teólogo de Nuremberg, com o nome Andreas Osiander. Kepler defendia que, assim como ele próprio, Copérnico era um realista e acreditava que seu modelo heliocêntrico descrevia a realidade física [10], não sendo, portanto, um mero artifício matemático para calcular os movimentos celestes.

$\mathrm{Na}$ cópia de Kepler aparece escrito, do seu próprio punho, acima do Ad lectorem o nome de Osiander. Pode-se imaginar que quando se deu conta do verdadeiro autor do Ad lectorem como deve ter ficado ansioso para revelar a todos não ser aquela introdução de Copérnico. No entanto, a anotação que pode ter tido a maior relevância para a gênese da lei das órbitas elípticas não foi feita por Kepler, e sim por Schreiber.

No fólio 143 aparece uma anotação com a caligrafia de Schreiber potencialmente inspiradora para Kepler em sua descoberta das leis do movimento planetário. Esta anotação é uma única palavra, em grego $\varepsilon \lambda \lambda \varepsilon \iota \psi \iota \varsigma$, que significa elipse [3].

Kepler narra em detalhes, como em um diário, sua jornada rumo à proclamação da lei das elipses em Astronomia Nova. A ideia central da grande obra de Kepler foi de calcular o movimento dos astros partindo de suas causas. Para que o Astronomia Nova fosse possível, Kepler tinha que ter acesso completo aos dados de Tycho, o que ele conseguiu de maneira controversa. O próprio Kepler em carta ao seu amigo Christopher Heydon datada de outubro de 1605, conta que "logo que Tycho morreu aproveitei a ausência e a falta de cuidados dos herdeiros para me apoderar das observações" [23].

Pode-se perceber três inovações relevantes em Astronomia Nova. A primeira foi colocar o Sol como centro geométrico e físico do sistema, pois para Kepler como o Sol era a fonte da força que regia o movimento dos planetas e, portanto, somente lhe caberia a posição central. A segunda foi considerar que todos os planetas estão em órbitas aproximadamente no mesmo plano, e este plano deve conter o Sol (ao contrário do que acontecia com os sistemas de Copérnico e Ptolomeu). A terceira foi a de se livrar da concepção platônica do movimento celeste circular e uniforme [23].

Kepler havia sido designado por Tycho para trabalhar nos dados do planeta Marte. Kepler prometera a Tycho que solucionaria o problema da órbita de Marte em oito dias; no entanto, sua promessa levou oito anos para ser cumprida. Pior para Tycho, que nunca viu o cumprimento da promessa, morrendo cerca de um ano depois de conhecer pessoalmente Kepler.

Somente depois de muitas tentativas é que Kepler resolveu abandonar as órbitas circulares para então tentar outra forma geométrica para a órbita de Marte. Antes de encontrar a figura geométrica que melhor se encaixava com os dados de Tycho, Kepler percebeu que a velocidade dos planetas dependia da distância do Sol. Também que a área varrida pela linha entre o planeta e Sol cobria áreas iguais em tempo iguais. Esta conclusão hoje é conhecida como $2^{a}$ lei de Kepler. Cronologicamente, a segunda lei de Kepler foi proposta antes da primeira conforme ele próprio relata em Astronomia Nova.

Depois de propor a $2^{a}$ lei, Kepler voltou ao problema da forma da órbita de Marte. Em 1602, já havia abandonado a forma circular e passou a tentar a forma oval sem sucesso. Em quatro de julho de 1603 escreve a um amigo dizendo que "se o formato fosse uma elipse perfeita, todas as respostas que procuro seriam encontradas" [23].

Apesar de ter a "dica" do formato das órbitas, Kepler só desistiu definitivamente das órbitas ovais após dezoito meses depois da carta a seu amigo. Após mais seis anos ele finalmente percebeu que a órbita de Marte era uma elipse sendo que o Sol está em um dos focos. Estava proposta a que viria a ser conhecida como $1^{a}$ lei de Kepler.

Na conclusão da natureza das órbitas elípticas, será 
que a anotação de Schreiber teve algum papel importante? Pode ser demasiado pensar que no meio das dúvidas sobre a forma das órbitas aquela única palavra desencadeou uma série de conclusões, levando-o à primeira lei. Entretanto esta hipótese pode corresponder à realidade e talvez Kepler nem tenha se dado conta disto.

Porém, não se deve em nenhum momento duvidar da genialidade de Kepler e do seu talento matemático e astronômico. Muito menos há a pretensão de se acusar Kepler de plágio ou algo semelhante. Entretanto é uma ideia provável que a pista dada pela anotação de Schreiber tenha auxiliado Kepler.

Em 1619, Kepler publica A Harmonia do Mundo. Nesta obra pode-se perceber a influência platônica e pitagórica muito grande em Kepler. Ele tenta, por exemplo, achar relações harmônicas entre as distâncias dos planetas [11]. Kepler faleceu em 15 de novembro de 1630 .

\section{Conclusões finais}

Quando Isaac Newton disse sua frase mais famosa "Se enxerguei mais longe fui porque me ergui sobre os ombros de gigantes" ele certamente estava citando, entre estes gigantes, Kepler [2]. Para Newton sua obra, culminando com a lei da gravitação universal, só fora possível graças à revolução iniciada por Copérnico.

Neste artigo, se pretendeu dar uma parcela de contribuição ao entendimento de alguns fatores que influenciaram o desenvolvimento da revolução copernicana e que culminaram na mecânica newtoniana. Tentouse contribuir para o esclarecimento de algumas ideias equivocadas que são transmitidas como fatos, seja para os alunos de ensino médio, quanto para os de ensino superior.

Com isto, espera-se que a ciência seja entendida como uma construção coletiva, produzida por seres humanos que sofrem influências históricas, sociais e filosóficas do contexto em que viveram.

\section{Agradecimentos}

Ao $\mathrm{CNPq}$ pelo fomento à divulgação científica, em especial Astronomia. Aos árbitros e editores da Revista Brasileira de Ensino de Física por darem contribuições valiosas para a qualidade do artigo. Ao professores Fernando Lang da Silveira da UFRGS e Francieli Socoloski Rodrigues da UFFS pela leitura prévia e todas suas sugestões pertinentes.

\section{Referências}

[1] J.C. Penereiro, Caderno Brasileiro de Ensino de Física 26, 173 (2009).

[2] R.S. Westfall, A Vida de Isaac Newton (Editora Nova Fronteira, Rio de Janeiro, 1995).

[3] O. Gingerich, O Livro que Ninguém Leu Em Busca das Revoluções de Nicolau Copérnico (Record, Rio de Janeiro, 2008).

[4] C.M. Porto e M.B.D.S.M. Porto, Revista Brasileira de Ensino de Física 31, 4601 (2009).

[5] I. Lakatos, La Metodologia de los Programas de Investigación Científica (Alianza Editorial, Madrid, 1989).

[6] T. Kuhn, A Estrutura das Revoluções Científicas (Perspectiva, São Paulo, 2009).

[7] P. Feyerabend, Contra o Método (Editora UNESP, São Paulo, 2007).

[8] D.P.A. Pilling e P.M.C. Dias, Revista Brasileira de Ensino de Física 29, 613 (2007).

[9] C.M. Porto e M.B.D.S.M. Porto, Revista Brasileira de Ensino de Física 30, 4601 (2008).

[10] R.R.F. Mourão, Copérnico Pioneiro da Revolução Astronômica (Odysseus Editora, São Paulo, 2003).

[11] A.S.T. Pires, Evolução das ideias da Fúsica (Editora Livraria da Física, São Paulo, 2008).

[12] P.M.C. Dias, Revista Brasileira de Ensino de Física 26, 195 (2004).

[13] G.G. Garbi, A Rainha das Ciências Um Passeio Histórico pelo Maravilhoso Mundo da Mantemática (Editora Livraria da Física, São Paulo, 2006)

[14] C.B. Boyer, História da Matemática (Editora Edgard Blücher, São Paulo, 1996).

[15] A. Medeiros e M.A. Monteiro, Caderno Catarinense de Ensino de Física 19, 28 (2002).

[16] F.L. Silveira, Caderno Brasileiro de Ensino de Física 19, 407 (2002).

[17] A. Koestler, Os Sonâmbulos (Ibrasa, São Paulo, 1961).

[18] J.M.F. Bassalo, Revista Brasileira de Ensino de Física 17, 284 (1995).

[19] A. Máximo e B. Alvarenga, Física: Volume 1 (Editora Scipione, São Paulo, 2008).

[20] J.E. Horvath, $O A B C D$ da Astronomia e Astrofísica (Editora Livraria da Física, São Paulo, 2008).

[21] K.S. Oliveira e M.F. Saraiva, Astronomia e Astrofísica (Editora Livraria da Física, São Paulo, 2004)

[22] T.S. Kuhn, A Revolução Copernicana (Ed. 70, Lisboa, 1990).

[23] R.R.F. Mourão, Kepler A Descoberta das Leis do Movimento Planetário (Odysseus Editora, São Paulo, 2008). 